\title{
A mediação na formação de professores em uma escola-piloto do Projeto UCA
}

\author{
Elizabeth A. L. M. Martines ${ }^{1}$, Aline M. Campos ${ }^{2}$, Daniele B. Brasil ${ }^{3}$, Leonir S. de \\ Souza $^{4}$ \\ ${ }^{1}$ Departamento de Biologia - Universidade Federal de Rondônia (UNIR) - 76.801-974 - \\ Porto Velho - RO - Brasil \\ ${ }^{2}$ Escola Municipal de Ensino Fundamental Nelso Alquieri, 76.889-000 \\ Cacaulândia - RO - Brasil
}

${ }^{3}$ Escola de Ensino Fundamental e Médio Tiradentes. 76.821-408 - Porto Velho - RO Brasil

${ }^{4}$ Departamento de Biologia - Universidade Federal de Rondônia (UNIR) - 76.801-974 - Porto Velho - RO - Brasil

bethmartines@gmail.com; alinemazorana@gmail.com;

bragabrasil.danieledgmail.com; leonirsalgmail.com

\begin{abstract}
This paper examines the work of mediation conducted by a UCA Coordinator in one of the pilot schools UCA Project in Rondonia to the integrated use of available technologies in the school, including the laptop of this project. The mediation coordinator was essential for teachers of early grades of elementary school were gradually overcoming initial resistance and incorporating laptops Project UCA in your routine classroom with greater security, integrating various tools as allies in the learning of their students especially in the process of reading and writing.
\end{abstract}

Resumo. Este artigo analisa o trabalho de mediação realizado por uma Coordenadora UCA em uma das escolas-piloto do Projeto UCA em Rondônia para o uso integrado das tecnologias disponíveis na escola, incluindo o computador portátil deste projeto. A mediação da Coordenadora foi fundamental para que os professores de séries iniciais do ensino fundamental fossem gradativamente vencendo resistências iniciais e incorporando os computadores portáteis do Projeto UCA em sua rotina de sala de aula com maior segurança, integrando várias ferramentas como aliadas nas aprendizagens de seus alunos, especialmente no processo de leitura e escrita.

\section{Introdução}

O Projeto Um Computador por Aluno (UCA) foi implantado em cinco escolas brasileiras em 2006 numa experiência chamada de Pré-piloto e, em 2010, ocorreu sua expansão para cerca de trezentas e cinquenta escolas, espalhadas por todos os estados, entre as quais se insere a Escola Municipal de Ensino Fundamental Nelso Alquieri, localizada no município de Cacaulândia / RO. O município é muito novo, pois, foi fundado em 1992 e localiza-se no interior do Estado de Rondônia, tendo recebido muitos migrantes vindos de várias partes do país nas décadas de 1980-90. Segundo o 
Instituto Brasileiro de Geografia e Estatística, possui uma população de 5.700 habitantes e ocupa uma área de $1.962 \mathrm{~km}^{2}$ no bioma amazônico.

Com a chegada do Projeto UCA, surgiu a necessidade de formação dos professores e gestores das oito escolas-piloto do estado de Rondônia e que ocorreu dentro de uma ampla rede que se formou entre a Universidade Estadual de Campinas (UNICAMP), a Universidade Federal de Rondônia (UNIR), os governos federal (MEC, CAPES, CNPq), estadual através da Secretaria de Educação / Núcleos de Tecnologia da Educação (SEDUC/NTE) e municipal através das Secretarias Municipais de Educação (SEMED) e a equipe técnica escolar, com destaque para a figura do Coordenador UCA na Escola. O Curso Formação Brasil disponibilizado pelo MEC ocorreu no período de novembro de 2010 a dezembro de 2012 (Martines e cols. 2012a), com muitos percalços e, partir de 2013, esta formação ficou por conta dos governos estaduais (através dos NTE) e municipais (através dos Nem).

Em cada escola participante do Projeto UCA em Rondônia foi designado pela própria equipe gestora um professor ou orientador educacional para atuar como um Coordenador UCA na Escola, sendo que alguns assumiram um importante papel no processo de formação para a utilização dos computadores portáteis por alunos e professores, pois dão o suporte pedagógico para os professores, auxiliando inclusive no desenvolvimento e planejamento de atividades com esse recurso tecnológico. (Brasil 2013).

O objetivo deste trabalho é analisar o papel da Coordenadora UCA de uma das oito escolas-piloto do Projeto UCA em Rondônia / Brasil, como resultado parcial de um estudo de caso desenvolvido numa concepção filosófica reivindicatória e participatória (Creswell 2010; Kemmis e Wilkinson 2002), no qual os Coordenadores UCA destas escolas tiveram participação ativa na pesquisa que ocorreu paralelamente com o curso Formação Brasil (Martines e cols. (2012b). É o caso da EMEF Nelso Alquieri, pois à medida que os professores vão adquirindo maior segurança estão integrando os equipamentos do Projeto UCA com outras mídias que o professor já utilizava e descobrindo novas ferramentas que atuam como poderosos aliados na luta diária para melhores aprendizagens de seus alunos, especialmente na leitura e escrita.

A coleta de dados ocorreu com a participação dos coordenadores UCA em cada uma das oito escolas, os quais elaboram projetos, relatórios e comunicações juntamente com pesquisadores da Universidade e que realizam visitas às escolas, observação participante, entrevistas, discutem e avaliam os documentos elaborados pelos professores e Coordenadores UCA e fazem comunicações dos resultados como coautores dos colaboradores das escolas.

Andrade e colaboradores (2012), ao analisar o papel que o uso de novas tecnologias vem adquirindo no cenário educacional num contexto em que sua utilização como recurso no processo de ensino-aprendizagem e sua ação no meio social vem aumentando rapidamente, concluem que a escola precisa e deve usar toda a tecnologia disponível para desenvolver seu trabalho pedagógico, oportunizando aos alunos e professores uma educação que dê condições deles participarem ativamente na sociedade contemporânea.

Durante a pesquisa realizada por estes autores, os pedagogos apontaram a formação continuada para o uso das novas tecnologias na educação essencial para que se efetive a integração de várias tecnologias educacionais (físicas, organizadoras e/ou simbólicas), de modo que ocorra um desenvolvimento profissional do professor até um 
ponto em que ele possa ter autonomia na utilização dessas ferramentas em sua prática pedagógica. Esses profissionais entendem que as novas tecnologias contribuem para a aprendizagem, porém alguns fatores, especialmente, a insegurança e a falta de preparo para explorar algo desconhecido, podem dificultar sua efetiva utilização.

A Coordenadora aqui citada concorda que este processo vem ocorrendo na escola em que ela atua.

\section{A escola como locus de formação}

A Escola Municipal de Ensino Fundamental Nelso Alquieri se localiza na zona urbana de Cacaulândia e, segundo a Secretaria da Escola, em junho 2013, possuía 389 alunos matriculados do $1^{\circ}$. ao $5^{\circ}$. Ano, sendo 208 no período a manhã e 181 no período da tarde e seu IDEB vem crescendo (em 2009 era 4,1 e em 2011 subiu para 4,7). Para atender este público-alvo, que possui muitos alunos que residem na zona rural e necessitam de transporte escolar para ter acesso à escola, a escola conta atualmente com 15 professores, sendo que 06 destes trabalham nos dois turnos (matutino e vespertino). A equipe técnica é composta de uma Diretora, uma Supervisora pedagógica, um Coordenador do Laboratório de Informática (LIE) e a Coordenadora UCA na Escola.

A Escola aderiu ao Projeto UCA em 2007 e, em meados de 2010, recebeu 502 computadores portáteis e uma rede de Internet que pode ser acessada pelos alunos e professores das salas de aula. Em novembro do mesmo ano iniciou-se o Curso Formação Brasil com a oferta do Módulo 1 (Apropriação Tecnológica), mas, com a mudança de governo tanto em nível federal como estadual, os demais módulos só voltaram a ser oferecidos no segundo semestre de 2011: Módulo 2 (Web 2.0), Módulo 3 (3a para os professores conhecerem os aplicativos do laptop educacional e $3 \mathrm{~b}$ para os gestores), Módulo 4 (Projetos e Currículo) e Módulo 5 (elaboração do Projeto de Gestão da Integração de Tecnologias no Currículo - PROGITEC -).

$\mathrm{Na}$ EMEF Nelso Alquieri a formação se deu como registrado nos Quadros 1 e 2, sendo que a Coordenadora UCA e outros professores da escola já tinham iniciado sua formação na área de tecnologia educacional quando iniciaram o Curso Formação Brasil, como mostra o Quadro 1.

\begin{tabular}{|c|c|c|}
\hline Cursos & Período & Concluintes \\
\hline Introdução a Educação Digital & 2008 & 09 \\
\hline Ensinando e Aprendendo com as TIC $(100 \mathrm{~h})$ & 2009 & 06 \\
\hline Elaboração de Projetos & 2010 & 10 \\
\hline
\end{tabular}

Quadro 1. Histórico da Formação da Coordenadora UCA e outros professores da EMEF Nelso Alquieri, anterior ao Curso Formação Brasil

O Quadro 2 mostra o desenvolvimento do Curso Formação Brasil na EMEF Nelso Alquieri, de Cacaulândia / RO, sendo que no Módulo 4 houve aproveitamento de estudos já realizados por dez professores em 2010, sobre elaboração de projetos. Estes professores tiveram participação ativa com os colegas no planejamento de projetos para serem executados integrando as tecnologias existentes na escola, prevista no Projeto de Gestão Integrada de Tecnologias (PROGITEC), elaborado com os gestores e professores durante o Módulo 3b e 5. 


\begin{tabular}{|c|c|c|c|c|c|}
\hline \multirow{2}{*}{ Cursos } & \multirow{2}{*}{ Período } & \multicolumn{4}{|c|}{ Dados cursistas (P=professores; G=gestores) } \\
\cline { 3 - 6 } & & Matriculados & Desistentes & Novatos & Concluintes \\
\hline Modulo 01 & Set. a Dez. 2010 & 21 & - & - & 21 \\
\hline Modulo 02 & Set. a Nov. 2011 & 21 & 01 & 05 & 20 \\
\hline Módulo 3a & Nov. a Dez. 2011 & 20 & 01 & - & 22 \\
\hline Módulo 04 & Abr/Ago 2012 & 22 & - & 03 & 22 \\
\hline $\begin{array}{c}\text { Módulo 3b } \\
\text { e Módulo 05 }\end{array}$ & $\begin{array}{c}\text { Nov 2011 a Dez } \\
2012\end{array}$ & 22 & - & - & 2 \\
\hline
\end{tabular}

Quadro 2. Histórico da formação do corpo docente da escola no Curso Formação Brasil

Dos vinte e um (21) professores/gestores que iniciaram o Módulo 01, um desistiu e cinco professores saíram da escola e foram substituídos, tornando necessário realizar com estes novos docentes a apropriação tecnológica iniciada no Módulo 1, o que foi feito pela Coordenadora UCA na Escola. No Módulo 03 ocorreu mais uma desistência e no Módulo 4 ingressaram mais três professores, de modo que em 2012 o curso se encerrou com 22 participantes. A escola conta com vários recursos tecnológicos, descritos no Quadro 3 e a formação incluiu o levantamento destes equipamentos e o planejamento da gestão integrada destes recursos no âmbito da escola (Silva e cols., 2012), unindo o Módulo 3b oferecido para os gestores e o Módulo 5.

\begin{tabular}{|c|c|c|}
\hline Descrição do Material & Quantidade & Conservação \\
\hline Computadores portáteis UCA & 502 & $\begin{array}{l}419-\text { Em uso } \\
03-\text { Com defeito }\end{array}$ \\
\hline Tevê 29 Polegadas, Analógica. & 03 & 02 em uso \\
\hline $\begin{array}{lll}\begin{array}{l}\text { Projetor } \\
\text { (PROINFO) }\end{array} & \text { Interativo } & \text { Multimídia } \\
\end{array}$ & 01 & Em uso. \\
\hline Projetor - BENQ MP515 Digital Projector & 01 & Com Defeito \\
\hline Notebook & 02 (01 Secretaria; 01 Sala de Recursos) & Em uso \\
\hline $\begin{array}{lccc}\text { Computadores do } & \text { Laboratório } & \text { de } \\
\text { Informática Educacional }- \text { PROINFO } & \end{array}$ & 16 (Desktop) & Em uso \\
\hline Sala de Recursos & $\begin{array}{l}\text { 01 Computador Desktop; } 01 \text { Televisor LCD } \\
\text { (Adaptado para portadores de necessidades } \\
\text { especiais); } 01 \text { teclado colmeia; } 01 \text { Notebook; } \\
\text { 01 Impressora. }\end{array}$ & Em uso. \\
\hline Sala de Professores & $\begin{array}{l}\text { 01 Computador Desktop Linux Ed.; } \\
\text { 01 Computador Desktop Windows; }\end{array}$ & \\
\hline Impressora a laser & $\begin{array}{l}02 \text { Sala Professores; } 01 \text { Supervisão; } 01 \\
\text { UCA; 01 LIE; 01 Direção; 02 Secretaria. }\end{array}$ & Todas em Uso \\
\hline Impressora Epson LX-300+II & 01 Sala dos prof. & Ultrapassada \\
\hline Máquina Digital - Olimpus 7.1 Megapixels & 01 & $\begin{array}{l}\text { Com defeito, mas } \\
\text { continua em uso. }\end{array}$ \\
\hline Máquina Digital - Sony 14.1 Megapixels & 01 & Em uso \\
\hline Aparelho de Som TOSHIBA TR 7046 U+ & 02 & Em uso \\
\hline Aparelho de DVD & 01 Biblioteca; 01 Pátio da Escola & Em uso \\
\hline
\end{tabular}

Quadro 3. Relação de equipamentos usados como recursos didáticos na escola 
Assim, para fazer a gestão da integração destas tecnologias entre si e com as mídias mais tradicionais no currículo em ação e a atualização de seu Projeto Político Pedagógico, a escola elaborou um Projeto de Gestão Integrada das Tecnologias (PROGITEC) como uma atividade do Curso Formação Brasil (Módulo 5), o qual vem orientando as ações desde 2011.

Entretanto, este curso ocorreu com muitos percalços e interrupções devido mudanças político-administrativas e, como muitos dos professores que atuam em escolas como a EMEF Nelso Alquieri não dominam o uso das Tecnologias de Informação e Comunicação (TIC), isto gerou resistências por parte destes profissionais diante das pressões para sua utilização, os quais tentam rejeitar a formação e sua utilização em sala, mantendo uma pedagogia centrada no professor. Segundo Lima Filho e colaboradores (2012), uma das principais características do ensino tradicional é a centralidade do processo ensino-aprendizagem no professor, o qual atua como fonte principal de informações, entretanto, eles concluem que, no novo cenário em que as TIC se fazem presentes, espera-se que o professor desempenhe outros papéis, tais como, organizador das situações didáticas, selecionando dentre a enorme variedade de recursos possíveis aqueles que sejam os mais adequados às situações didáticas específicas de sua sala de aula e no tempo adequado.

Lima Filho e colaboradores (2012) analisaram planejamentos de aulas de ciências disponibilizados no Portal do Professor que evidenciam uma variedade de recursos e estratégias adotadas indicando uma tendência de diversificação na abordagem dos conteúdos das disciplinas. Nas 26 aulas analisadas, identificaram-se 25 estratégias diferentes. Segundo eles, esta diversidade é um aspecto importante na medida em que explora os conteúdos estudados a partir de perspectivas diferentes, possibilitando ao aluno analisá-los sob diferentes ângulos. Por exemplo: diversas atividades planejadas propunham que o aluno desenvolvesse ações de elaboração e apresentação dos slides, realização de experimentos, confecção de tabelas e gráficos, dentre outras. Essa perspectiva retira o aluno da condição de mero expectador, conferindo-lhe papel mais ativo. Algumas situações requerem que ele exercite a autoria, outras proporcionam momentos de reflexões e discussões. Entretanto, segundo eles, o fato de constar no planejamento do professor, diversas atividades coletivas não garante a colaboração entre os alunos ou o compartilhamento de significados, negociação de pontos de vista e troca de entendimentos sobre saberes e percursos a serem adotados. Mas, já é um indício consistente, que demonstra que os docentes estão percebendo a relevância de incentivar a adoção de práticas colaborativas no contexto de sala de aula.

Eles também observaram que a utilização do laptop educacional do UCA foi prevista, em maior ou menor medida, em todas as estratégias analisadas, ora como suporte, ora para registro das atividades, o que não garante usos inovadores e criativos. Estas novas funções exigem a mediação de profissionais mais experientes no cotidiano da escola para auxiliá-los nestas novas atribuições dos professores da educação básica. Na próxima seção, discutimos o conceito de mediação e o papel dos mediadores mais experientes.

\section{A mediação da Coordenadora UCA no processo formativo dos professores}


O conceito de mediação aqui utilizado se apóia na teoria histórico-cultural, a qual permite pensar o computador e a Internet como instrumentos de aprendizagem. $\mathrm{O}$ conceito de instrumento em Vigotski indica a possibilidade de três classes de mediadores: a pessoa do outro, ferramentas materiais e ferramentas psicológicas. Essas três mediações ocorrem no uso do computador/Internet: a mediação da ferramenta material (o computador enquanto máquina); a mediação semiótica (através da linguagem); e a mediação com os outros (interlocutores). (Freitas 2008).

Segundo os teóricos desta corrente, enquanto ser biológico, o homem se humaniza ao se apropriar dos conhecimentos produzidos em uma dada cultura através da utilização de instrumentos, tanto os materiais como os psicológicos, uma vez que, ao modificar o meio ou a natureza com o uso de ferramentas, o ser humano também se modifica criando funções novas, especialmente, as Funções Psicológicas Superiores, como linguagem, pensamento lógico-científico, planejamento e tomada de decisões, entre outras. Desta forma, em sua relação com o mundo e mediado por instrumentos, por símbolos e por pessoas mais experientes e que conhecem estas ferramentas e possuem os significados destes símbolos que são desenvolvidos culturalmente, o ser humano passa a criar formas de ação, que o distingue de outros animais (Bruner 2001).

Freitas (2008) defende o computador e a Internet como instrumentos de aprendizagem através dos quais ocorre uma tripla mediação, e, neste artigo, ampliamos sua reflexão defendendo-os como instrumentos de ensino e destacando a importância da mediação com o outro na formação permanente do professor para sua utilização de forma que estes possam exercer seu papel mediador no processo de aprendizagem de seus alunos. A autora apresenta as dificuldades da escola para a incorporação do computador/Internet à prática pedagógica dos professores e reflete sobre o papel mediador exercido por estas tecnologias, defendendo-as como instrumentos tecnológicos e simbólicos, ao mesmo tempo. "Ao explorar essas possíveis mediações salientamos a importância que assume o professor como o responsável pela mediação humana no uso do computador e da internet na escola como instrumentos de aprendizagem." (Freitas 2008, p. 41).

Os instrumentos materiais promovem uma mediação entre as características naturais do homem e a natureza e, ao transformá-la pelo uso destas ferramentas, o próprio homem se modifica com o desenvolvimento de novas funções. Quando isto acontece, formam-se instrumentos psicológicos que promovem a mediação semiótica (significados construídos na linguagem) através da interação social dentro de um contexto cultural (mediação com outros seres humanos). Os instrumentos do passado precisam ser significados para que as novas criações se tornem possíveis, tanto pela ruptura quanto pela continuidade, ligando as pessoas através das gerações e aos seus contemporâneos.

O computador e sua interligação em rede se constituem em instrumentos contemporâneos de enorme presença em nosso contexto social: para o trabalho, utilização doméstica, entretenimento e para fins educacionais nas escolas, de tal maneira que podemos falar de uma cultura digital na qual as crianças e jovens estão se desenvolvendo (os nativos digitais). Mas, muitos membros de nossas comunidades estão excluídos ou marginalizados nessa cultura (também chamados de estrangeiros digitais) (Freitas 2008), por não dominarem o uso destas tecnologias e entre eles, estão muitos professores, que ainda necessitam desenvolver o domínio técnico destas ferramentas e, ainda, conhecer seu uso pedagógico para potencializar as aprendizagens de seus alunos. 
Assim como os professores são importantes como mediadores para que os alunos possam se beneficiar do uso destas ferramentas contemporâneas em sua aprendizagem, analisamos a importância da mediação de pessoas mais experientes para quebrar resistências naturais (e até positivas) de professores que se encontram nesta condição marginal ou de exclusão nesta nova cultura. Mas, como fazer isto? Pela coação? Muitos têm adotado esta postura, especialmente no âmbito dos órgãos públicos, nas coordenações de projetos de mudanças curriculares etc. Ou podemos usar de colaboração e cooperação?

O trabalho mediador realizado pela Coordenadora UCA desta escola se deu desde o início do curso Formação Brasil, uma vez que ela tinha maior domínio das ferramentas disponibilizadas pelo Projeto UCA a todos os professores e alunos da escola. Ao longo de 2011 foi percebendo as dificuldades dos colegas e a resistência de muitos para incorporar estas tecnologias em suas rotinas de sala de aula. No início do ano letivo de 2012, ela disponibilizou uma lista de links com estratégias e recursos no Servidor do Projeto UCA, obtidos em uma pesquisa realizada no Portal do Professor e outros sites, para que, no decorrer do ano, os professores fossem utilizando-os para planejar suas aulas com mais facilidade. Esta lista é atualizada sempre que um novo recurso é encontrado a partir de demandas específicas dos professores. Outros profissionais da escola colaboram com este trabalho (como a Coordenadora Pedagógica e o Coordenador do Laboratório de Informática) e a equipe divulga aulas que "deram certo" para os professores analisarem e decidir usar em sala de aula, mas, reconhecem que nem todos os docentes estão abertos a estas inovações.

A Coordenadora UCA nesta escola fala das intervenções que ela e outros membros da equipe pedagógica têm realizado para vencer estas resistências:

"Frente à resistência encontrada no cotidiano, procuramos questionar os professores sobre quais são as dificuldades que seus alunos vêm apresentando durante suas aulas. Quando o mesmo coloca, como por exemplo: Dificuldade para aprender a subtrair, apresentamos as atividades que podem ser realizadas por meio do laptop, e que o uso dele pode ajudar a trabalhar de maneira diferenciada sem a necessidade de deixar seu conteúdo de lado. Por que, quando a proposta de atividade é apresentada por meio do 'uquinha' o interesse do aluno em realizar a atividade é bem maior. Observando o conteúdo que está sendo trabalhado em sala de aula e mostrando ao professor a possibilidades de atividades que podem ser desenvolvidas com o uso do Laptop, muitas delas disponíveis no Portal do Professor ou em outros sites. Procuramos mostrar para o professor que, se ele planeja uma aula sobre determinado conteúdo com o uso de diversas mídias, ou seja, por meio de um vídeo, simulação, leitura, leitura de imagens, áudio e outros, buscando explorar todos os sentidos do aluno a possibilidade de aprendizagem se torna maior.". (Relatório 2012 da Coordenadora UCA na Escola).

Outra ação importante desenvolvida na escola a partir do PROGITEC se deu diante da constatação de que, no Brasil, há um grande número de alunos que apresentam baixa aprendizagem da leitura e escrita, com dificuldades em compreender um texto, o que se reflete nos resultados do Índice de Desenvolvimento da Educação Básica (IDEB). No estado de Rondônia não é diferente: o IDEB indica as mesmas falhas e deficiências do restante do país no que diz respeito à capacidade de leitura e escrita dos alunos. E na EMEF Nelso Alquieri no município de Cacaulândia, os professores afirmam que as 
maiores dificuldades de aprendizagem dos alunos também estão no campo da leitura, escrita e compreensão textual e se preocupam com isto. Assim, diante da dificuldade apresentada pelos alunos e da preocupação dos professores, a equipe pedagógica da escola decidiu dar maior atenção à aprendizagem da leitura, escrita e interpretação de textos e elaborou com os professores, um projeto planejando o desenvolvimento de atividades com o uso da Mídia Impressa (livros) e da Mídia Digital (laptops do Projeto UCA). É na perspectiva de melhorias da aprendizagem dos alunos que a Escola procura realizar um trabalho de interação entre Livros e Um Computador por Aluno.

\subsection{Uso de diferentes Mídias na sala de aula e a mediação dos professores}

Este projeto que integra livros com o laptop educacional passou a ser um desafio para os educadores da escola, pois, precisam desenvolver o papel de mediadores ou orientadores da aprendizagem, com um novo recurso, explorando as utilidades e possibilidades da Mídia Digital junto com uma que já dominavam (Mídia Impressa). Alguns dos envolvidos são conscientes das possibilidades que a ferramenta oferece e concordam com Fagundes, Sato e Maçada (1999) que dizem que, já que não é possível trazer toda a vida para a escola, é possível enriquecer o seu espaço com objetos digitais e, como na EMEF Nelso Alquieri todos os professores e alunos possuem um computador com acesso a redes de conexão, novos espaços são, assim, criados para a aprendizagem da leitura e escrita, possibilitando o acesso a diversos livros, lugares e histórias sem sair da sala de aula, ingressando esta comunidade na cibercultura.

A equipe pedagógica da escola acredita que, quanto mais contato o aluno tem com o livro, maior será seu interesse pela leitura e que o professor deve assegurar às crianças o acesso aos livros, agindo como elemento facilitador e incentivador da criança na construção do hábito da leitura, tornando estes momentos agradáveis e atrativos para mobilizar a atenção das crianças de forma prazerosa.

Diante do desafio em trabalhar com o computador portátil e livros na aprendizagem da leitura, os professores da Escola Nelso Alquieri foram orientados a usar o Navegador Chromiun, acessível depois da troca do sistema operacional dos laptops UCA (o Metasys que veio instalado foi substituído pelo UbuntuUCA) e que disponibiliza as mesmas ferramentas do Google Chrome, os quais vêm fazendo grande sucesso graças à simplicidade de uso e velocidade de conexão com a Internet. Com este navegador, os professores sentiram mais segurança e facilidade no uso dos recursos digitais, encontrando leituras e situações de compreensão textual em sites apropriados.

A fim de auxiliar e facilitar o trabalho dos professores em sala de aula, a equipe pedagógica os capacitou para uso deste navegador e disponibilizou no Servidor UCA da Escola uma lista de links que dão acesso a textos, histórias, livros digitais, livros em áudio, entre outros, que os professores acessam ao fazerem seus planejamentos. Os professores também utilizam o Software "Hot potatoes" e com orientações da Coordenadora UCA na Escola, elaboram atividades e as disponibilizam no Servidor, para que os alunos possam acessá-las por meio da rede local. Este processo permite ao professor ser o autor de algumas atividades desenvolvidas em sala de aula, paralelamente ao uso de outras desenvolvidas por professores mais experientes no uso das TIC na educação. Nesta etapa de planejamento das atividades, os professores selecionam textos, recursos, descrevem os objetivos e estratégias e passam para o desenvolvimento da atividade em sala de aula, algumas delas citadas a seguir: 
"Antes de entregar o Laptop ou o livro para os alunos, o professor os orienta a respeito da atividade que será desenvolvida, descreve no quadro os passos necessários para acessar o texto e entrega o recurso na mão dos alunos. Com auxílio da bibliotecária ou dos alunos monitores, ou da coordenação UCA da Escola, Professor e alunos realizam a leitura individual ou coletiva, em seguida os alunos fazem a compreensão textual, por meio de questionamento oral ou no próprio laptop. Ou o aluno lê o livro, depois é convidado a se aproximar da caixa de som e utilizar o microfone para contar o que entendeu da história e o professor vai conduzindo os alunos na compreensão do texto. Sendo que a atividade pode encerrar neste momento na biblioteca ou dar continuidade com a produção de novos textos com base nas histórias que conheceram. A produção de texto pode ser feita tanto no caderno quanto no editor de textos do laptop educacional." (Relatório 2012 da Coordenadora UCA na Escola).

Assim, o projeto tem ajudado os professores a saírem de uma prática centrada no professor para uma prática em que o aluno se torna mais ativo; passaram a propor mais atividades de análise de textos, questionando os discentes a respeito dos textos lidos, instigando a reflexão e o envolvimento com o assunto em questão. Estes docentes passaram a desenvolver o papel de mediadores nos processos de ensino e aprendizagem, ao ajudarem seus alunos a compreenderem os sistemas simbólicos contidos nos livros e outras mídias, ao mesmo tempo em que usam com seus alunos instrumentos que também fazem a mediação entre o saber de alunos (com pouco acesso a bens culturais valorizados na contemporaneidade) e os conhecimentos escolares. Mas, para chegar a este ponto, precisaram da mediação prudente e cuidadosa da equipe pedagógica e gestores, especialmente da Coordenadora Uca na Escola.

\section{Considerações finais}

Apesar das dificuldades pedagógicas para o desenvolvimento das atividades em sala de aula com os laptops, com a mediação da Coordenadora UCA nesta escola, os professores estão ousando inovar suas práticas. Mesmo com as dificuldades e limitações, os professores reconhecem que os alunos se mostraram mais interessados quando as novas propostas de atividades foram realizadas. Utilizar a biblioteca com mais frequência e utilizar os laptops para ler e desenvolver atividades de interpretação trouxe inovações na prática dos professores desta escola nos momentos de leitura. $\mathrm{O}$ projeto de integração da mídia impressa e a mídia digital foi avaliado pelos professores e todos afirmaram que houve bons avanços e a equipe pedagógica da escola tem convidado os alunos envolvidos para realizar leituras individuais em diferentes momentos e também concluiu que houve bons avanços na aprendizagem dos alunos.

Os professores se sentem animados a continuar este trabalho quando percebem o seu próprio desenvolvimento, os de seus alunos e do IDEB da escola, que vem melhorando a cada avaliação (em 2009 era 4,1 e em 2011 subiu para 4,7). Entretanto, para que pudessem exercer este importante papel de mediadores na aprendizagem de seus alunos, foi necessária a mediação da coordenadora UCA na Escola e demais membros da equipe pedagógica e gestora para que os professores fossem se integrando gradativamente na cultura digital, usando o computador e a Internet como instrumentos de ensino.

O uso da Mídia digital pelos professores e alunos da EMEF Nelso Alquieri foi possível graças ao Projeto UCA que dotou as crianças e seus mestres com um computador portátil e instalou a rede de Internet na escola. Mas, também, graças à 
capacitação oferecida e ao esforço dos professores, mas, principalmente, graças à mediação realizada pela equipe pedagógica, na qual a Coordenadora UCA desta escola se inclui. $O$ trabalho da Coordenadora UCA na Escola tem sido decisivo para a continuidade da formação em serviço, a fim de que os professores de séries iniciais do ensino fundamental possam gradativamente ir vencendo resistências iniciais, ganhando competências e incorporando os computadores portáteis do Projeto UCA em sua rotina de sala de aula.

\section{Referências}

Andrade, E. D. de; Talamini, J. L.; Kuligovski, M. P. (2012). O pedagogo e as novas tecnologias. Anais do XVIII WIE. Rio de Janeiro.

Brasil, D. B. A utilização do laptop educacional como instrumento de ensino de ciências em Rondônia. Dissertação. Mestrado de Psicologia / UNIR. Porto Velho, 2013.

Creswell, J. W. (2010). Projeto de pesquisa: métodos qualitativo, quantitativo e misto. Porto Alegre: ArtMed.

Fagundes, L. C.; Sato, L. S.; Maçada, D. L. Projeto? O que é? Como se faz? In: FAGUNDES, L. C.; SATO, L. S.; MAÇADA, D. L. Aprendizes do futuro: as inovações começaram! Coleção Informática para a mudança na Educação. Brasília: MEC, 1999. p. 15-26.

Kemmis, S.; Wilkinson, M. (2002). A pesquisa-ação participativa e o estudo da prática. In: PEREIRA, J. E. D.; ZEICHNER, K. M. (Orgs.). A pesquisa na formação e no trabalho docente. Belo Horizonte: Autêntica. Pp. 43-66.

Lima Filho, C. B.; Castro Filho, J. A. de; Campos, A. S. (2012). O Ensino de Ciências em Escolas UCA: Uma Análise das Estratégias de Mediação Didática. Anais do XVIII WIE. Rio de Janeiro.

Martines, E. A. L. de M.; Valente, J. A.; Vieira, M. P. e Souza, L. dos S. (2012a). Reflexões sobre a formação para uso do computador na implantação do Projeto UCA em Rondônia. Anais do III Web Currículo. Campinas.

Martines, E. A. L. M.; Souza, L. S. de; Brasil, D. B.; Lacerda, M. P. R. (2012b). Estudo de caso da implantação do Projeto "Um Computador por Aluno" em Rondônia. In Sampaio, F. F. e Elia, M. da F. (Orgs.). Projeto Um computador por Aluno: pesquisas e perspectivas. Rio de Janeiro: UFRJ. Pp. 122-132.

Silva, S. C. da; Campos, R. M.; Gervásio, R. (2012). Planejamento participativo para integração de tecnologias ao currículo escolar. Anais do VI Simpósio Linguagens e Identidade da/na Amazônia Sul-Ocidental / V Colóquio Internacional "As Amazônias, as Áfricas e as Africas na Pan-Amazônia. Rio Branco / AC.

Indezeichak, S. T. (2008). O professor de língua portuguesa e o ensino mediado pela tecnologia. Centro Estadual de Educação Básica para Jovens e AdultosUniversidade Estadual de Ponta Grossa. Mato Grosso do Sul. 